\title{
A study on fatigue crack growth in dual phase martensitic steel in air environment
}

\author{
K V SUDHAKAR* and E S DWARAKADASA ${ }^{\dagger}$ \\ Department of Materials Engineering, Western Michigan University, Michigan 49008, USA \\ 'Department of Metallurgy, Indian Institute of Science, Bangalore 560 012, India
}

MS received 15 November 1999; revised 29 March 2000

\begin{abstract}
Dual phase (DP) steel was intercritically annealed at different temperatures from fully martensitic state to achieve martensite plus ferrite, microstructures with martensite contents in the range of 32 to $76 \%$. Fatigue crack growth (FCG) and fracture toughness tests were carried out as per ASTM standards E 647 and E 399, respectively to evaluate the potential of DP steels. The crack growth rates $(\mathrm{d} a / \mathrm{d} N)$ at different stress intensity ranges $(\Delta K)$ were determined to obtain the threshold value of stress intensity range $\left(\Delta K_{\text {th }}\right)$. Crack path morphology was studied to determine the influence of microstructure on crack growth characteristics. After the examination of crack tortuosity, the compact tension (CT) specimens were pulled in static mode to determine fracture toughness values. FCG rates decreased and threshold values increased with increase in vol.\% martensite in the DP steel. This is attributed to the lower carbon content in the martensite formed at higher intercritical annealing (ICA) temperatures, causing retardation of crack growth rate by crack tip blunting and/or deflection. Roughness induced crack closure was also found to contribute to the improved crack growth resistance at higher levels of martensite content. Scanning electron fractography of DP steel in the near threshold region revealed transgranular cleavage fracture with secondary cracking. Results indicate the possibility that the DP steels may be treated to obtain an excellent combination of strength and fatigue properties.
\end{abstract}

Keywords. Dual phase (DP) steel; fatigue crack growth; fracture toughness; stress intensity range; intercritical annealing; crack closure.

\section{Introduction}

The influence of microstructure on fatigue crack growth (FCG) behaviour in steels has been a subject of considerable research interest for many years. Such microstructural effects on FCG are found to be most significant in the near threshold regime $\left(\Delta K_{\mathrm{th}}\right)$ where growth rate of long cracks is negligible, i.e. less than $10^{-7} \mathrm{~mm} /$ cycle (Masounave and Bailon 1976; Ritchie 1977, 1979; Lucas and Gerberich 1981; Suresh et al 1982). Evaluation of newer materials with improved combinations of strength, ductility and toughness has led to the emergence of a series of composite structures, in which dual phase (DP) steels represent a distinguished class. DP steels were developed to satisfy an increasing need, primarily in the automobile industry, for new high strength steels that permit weight reduction without sacrificing formability nor dramatically increasing costs. The specific potentials that have been technologically exploited are their superior ductility and formability characteristics compared to HSLA or conventional plain carbon steels of similar strength level.

\footnotetext{
*Author for correspondence
}

Suzuki and McEvily (1979), who developed two different duplex microstructures in AISI 1018 steel reported some of the notable results in terms of fatigue properties. Two heat treatments A and B were given to DP steel to obtain structures with about 36 and 39 wt.\% martensite respectively. The specimens for the FCG tests were of the non-standard compact tension type, having a thickness of $6.3 \mathrm{~mm}$ and width $57.2 \mathrm{~mm}$. The heat treatment B led to a remarkable improvement in threshold level. However, at a higher crack propagation rate, the difference between the two decreased. Dutta et al (1984) studied the characteristics of FCG in DP steels in a high purity $\mathrm{Fe}-2 \mathrm{Si}-0 \cdot 1 \mathrm{C}$ steel with the objective of developing ferrite-martensite microstructure with maximum resistance to crack growth extension, while maintaining high strength levels. Minakawa et al (1982), Ramage et al (1984), Mediratta et al (1985), and Jian Ku Shang et al (1987) have also studied the effects of microstructure on FCG behaviour in DP steels.

Any emergence of high strength DP steel, with marginal sacrifice of ductility, will be useful for structural applications in thick sections rather than their current employment in automotive components. The integrity of such structural materials has to be examined using fracture mechanics principles. This, in turn, necessarily demands the search for microstructure-fracture toughness 
correlation in such materials, in addition to conventional assessment of tensile, hardness and impact properties. Furthermore, if such structural materials need to be subjected to cyclic loading, their FCG behaviour also needs to be carefully assessed. As of now, no literature is available on the development of DP steels (containing higher martensite content) with commercial potential for structural applications. In all the previous studies made on DP steel, there is very little data available on fracture toughness. FCG studies were made only on non-standard specimens having a maximum thickness of $6.5 \mathrm{~mm}$. The objective of this investigation is to emphasize on fracture toughness and FCG behaviour of high martensite DP steel (Sudhakar 1996).

\section{Material and heat treatment}

\subsection{Material}

C 1003 steel, commercially microalloyed steel (in the hot rolled condition) was used in the present investigation. The steel was analyzed using a spectrovac (Model-1000 DV4) and the composition is given in table 1.

Half size compact tension (CT) specimens were machined to the dimensions as per ASTM E399 standard. All the machined CT specimens were austenitized at $920^{\circ} \mathrm{C}$ in a muffle furnace, homogenized for $60 \mathrm{~min}$ and then quenched in $9 \%$ brine solution to get a fully martensitic structure. This is to ensure the same starting microstructure in all the cases. The individual CT specimens were intercritically annealed between $730^{\circ} \mathrm{C}$ and $850^{\circ} \mathrm{C}$ (hold time, $1 \mathrm{~h}$ ) to get a dual phase structure having a martensite content varying between 32 and $76 \%$. The volume fraction of martensite was computed using an automated image analyzer (Quantimet-520 having a measuring accuracy of $1 \%$ ) as a ratio of the area of martensite to a total area.

\subsection{Fatigue crack growth and fracture toughness test}

Fatigue crack growth tests were carried out as per ASTM E647 standard on CT specimens on an INSTRON-UTM (Model 8032) servohydraulic closed loop test system of capacity $100 \mathrm{kN}$. Load shedding technique was used to determine the crack growth rates at different $\Delta K$ values. Crack growth was monitored using a traveling microscope (with a resolution of $0.01 \mathrm{~mm}$ ) on optically polished surfaces. To determine the threshold stress intensity $\left(\Delta K_{\mathrm{th}}\right)$ values, $0.05 \mathrm{~mm}$ crack extension was monitored at each load decrement, keeping the load ratio $(0 \cdot 1)$ constant. Tests were terminated when the physical value of crack growth became negligible even after one million cycles of stress. Atleast two specimens were tested for each microstructural condition.

The precracked specimens (from the FCG test) were subjected to load-displacement test under stroke-control mode, at a displacement rate of $2 \mathrm{~mm} / \mathrm{min}$, till fracture. Using the test program (software) the load corresponding to an apparent $2 \%$ increment in crack extension was established. From this value of $P_{\mathrm{Q}}$, apparent value of fracture toughness, $K_{\mathrm{Q}}$ was calculated as per ASTM standard E399.

\section{Results and discussion}

\subsection{Tensile test}

Tensile test results for the DP steel with martensite content varying between 32 and $76 \%$ are shown in figure 1 . It is readily seen that the yield strength (YS) and ultimate tensile strength (UTS) increased with an increase in martensite content up to a maximum of $76 \%$ martensite. As expected, elongation marginally decreased. The increase in strength is mainly attributed to (a) the load bearing capability of martensite in the DP structures, and (b) the deformation in the ferrite phase is constrained by martensite. It is widely reported (Matsuoka and Yamamori 1975; Rashid 1979; Speich 1981) that the YS and UTS of DP steels are linearly related to the volume fraction of martensite but are independent of its carbon content. The variation of strength obeys the law of mixtures (Mileiko 1969) as per the relation,

$$
S=S_{\alpha} V_{\alpha}+S_{\mathrm{m}} V_{\mathrm{m}}
$$

where, $S$ is the nominal flow stress of the composite, $V_{\alpha}$ and $V_{\mathrm{m}}$ are volume fractions of ferrite and martensite and $S_{\alpha}$ and $S_{\mathrm{m}}$ are respectively the nominal stresses in the ferrite and martensite. Equation (1) is based on an assumption that only two phases are present in the DP steel viz. ferrite and martensite.

\subsection{Fatigue crack growth behaviour}

FCG behaviour of intercritically annealed DP steel samples having different volume\% of martensite, in labo-

Table 1. Chemical composition of C 1003 steel.

\begin{tabular}{lccccccccccc}
\hline Element & $\mathrm{C}$ & $\mathrm{Mn}$ & $\mathrm{Si}$ & $\mathrm{S}$ & $\mathrm{P}$ & $\mathrm{Cr}$ & $\mathrm{Mo}$ & $\mathrm{V}$ & $\mathrm{B}$ & $\mathrm{N}$ \\
\hline$\%$ Wt. & 0.14 & 1.36 & 0.50 & 0.007 & 0.028 & 0.042 & 0.115 & 0.062 & 0.002 & 0.004 \\
\hline
\end{tabular}


ratory air environment, is shown in figure 2. The FCG rates were found to decrease and $\Delta K_{\text {th }}$ increase with an increase in martensite content. It is clear that a remarkable difference can be seen around $\Delta K_{\text {th }}$, although the crack propagation rates are observed to be only marginally different at high $\Delta K$. Threshold value of the stress intensity factor is increased by about $85 \%$ for DP steel containing $76 \%$ martensite than that containing $32 \%$ martensite. The decrease in FCG rate with an increase in martensite content of DP steel is attributed primarily to the two mechanisms, viz. (i) lower carbon content in martensite formed at higher ICA temperatures, and (ii) roughness induced crack closure.

Speich (1981) observed that the martensite formed at higher ICA temperatures contained lower carbon contents. From this study, it may be concluded that the martensite with lower carbon content was tougher, and thereby effective in reducing the crack tip driving force by mechanisms of crack tip blunting and deflection. Roughness-induced crack closure resulting from fracture surface asperities due to shear displacements, inelastic crack tip deformation and surface oxidation effects, was also found to have an influence on FCG rates. It is evident from figure 3 that the fracture surface roughness (fracture surface roughness was defined as the difference in height between the 'peaks' and 'valleys' of the fracture surface, measured using TALYSURF-Model 3 instrument having an accuracy of $1 \mathrm{~nm}$ ) increases with an increase in martensite content up to $76 \%$. This increased degree of fracture surface roughness is responsible for the decrease in FCG rate with an increase in martensite content. The linear dependence (as shown in figure 3 ) of $\Delta K_{\text {th }}$ on volume $\%$ martensite (VPM) can be expressed in the form

$$
\Delta K_{\mathrm{th}}=a+b(\mathrm{VPM})
$$

where $a$ and $b$ are constants with values of 1.75 and $0 \cdot 075$, respectively.

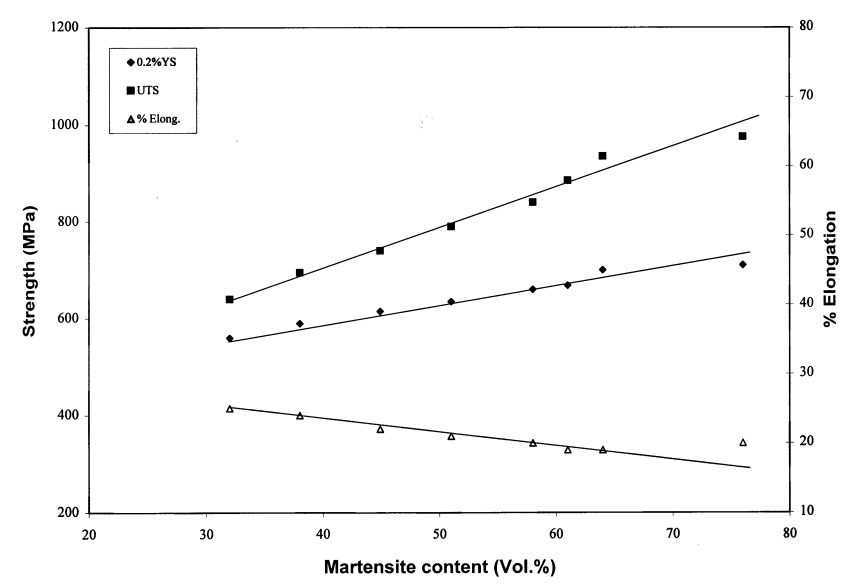

Figure 1. Tensile behaviour of DP steel.
It is clear that the FCG behaviour of DP steel is very sensitive to the microstructure of the material in the nearthreshold region. In general, this sensitivity seems to arise particularly as a result of microstructure-induced crack closure, which effectively shields the crack tip from the far field stress intensity range.

\subsection{Microstructure and crack path morphology}

Typical ICA microstructures and crack path morphology for different vol.\% of martensite are shown in figures 4 and 5, respectively. Martensite is platelet in morphology in most of the microstructures except blocky in morphology at higher volume percentages. Detailed microscopic examination was carried out for crack path morphology of DP steel samples containing martensite from $32 \%$ to $76 \%$. In general, microstructures revealed (a) more severe/wider crack paths at higher crack growth rates, and (b) tortuous/narrow crack paths at near threshold regions, in all the cases. The crack path was relatively more zigzag and tortuous for the DP steel containing higher volume content of martensite. It may be seen in figure 5 a through $5 \mathrm{~h}$ that the crack propagation was random (no specific preferential path) passing through ferrite and martensite and the interface of ferrite/martensite phases.

The morphology of martensite in DP steels is known to cause significant differences in crack deflection and roughness-induced crack closure. In the present microstructure, crack tip shielding, an additional crack closure mechanism, also contributes to the retardation of crack growth. Crack tip shielding mechanism appears to play a role as discussed below.

There are primarily two effects that lead to higher crack closure level. The first is caused by the martensite being the continuous phase. A martensite envelope will surround the crack tip in ferrite. Upon application of load, the martensite will be the load-bearing phase thus shielding the crack tip from a part of the applied load. This results in reduced effective stress intensity range at the crack tip.

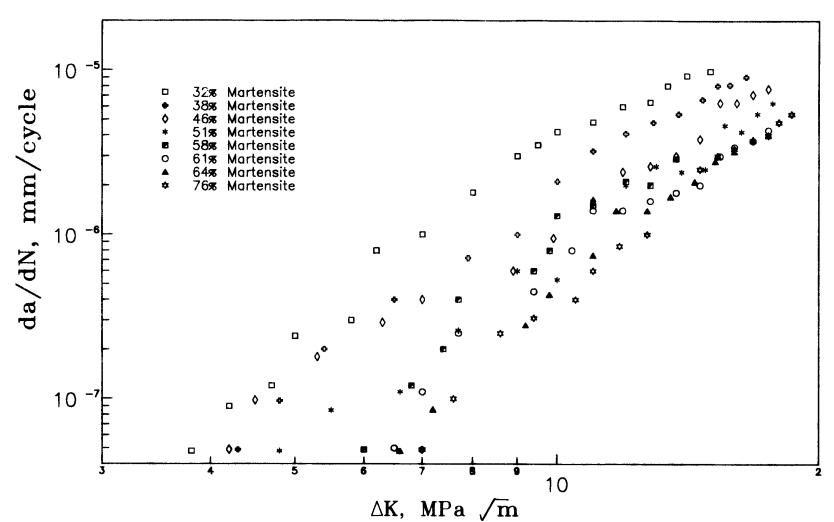

Figure 2. FCG behaviour of DP steel in laboratory air. 


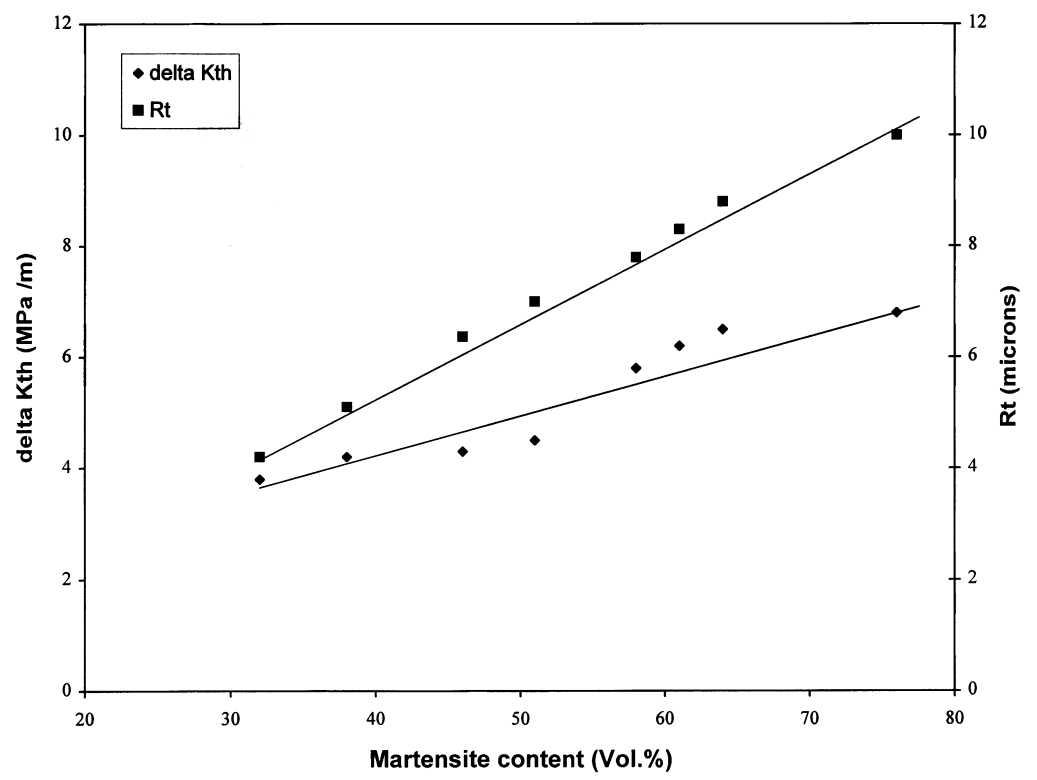

Figure 3. Variation of threshold stress intensity factor and fracture roughness with vol.\% martensite.
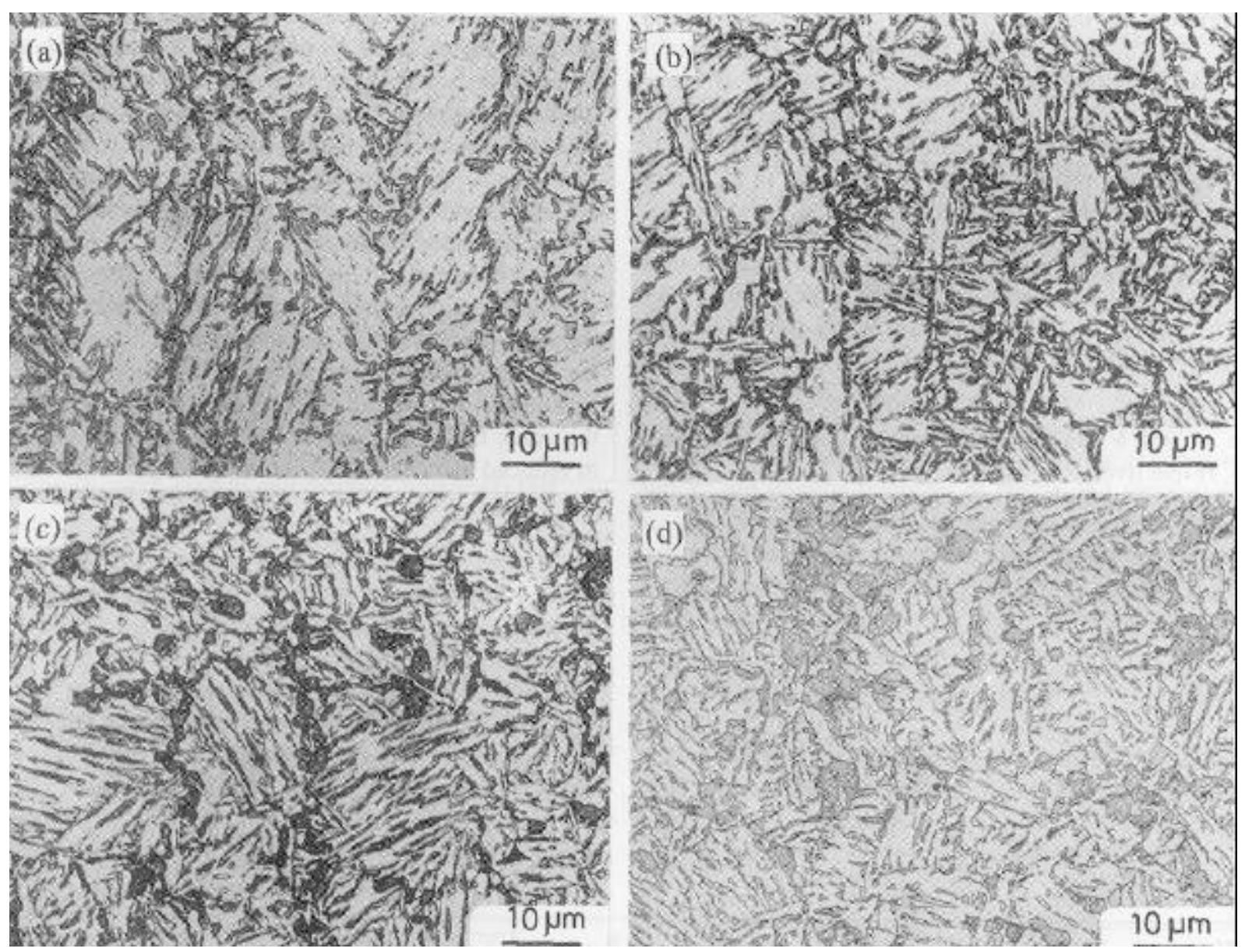

Figure 4. Intercritically annealed optical microstructures (a) 32\% martensite, (b) $46 \%$ martensite, (c) $58 \%$ martensite and (d) $64 \%$ martensite. 
The second effect of the continuous martensite microstructure is brought about by an interaction of the martensite with the ferrite. In the present microstructure, a martensite envelope surrounds the crack growing in the ferrite phase. It has been shown that the martensite in a dual phase structure will constrain the plastic deformation in the ferrite phase (Yang and Liu 1979; Minakawa and McEvily 1981). This constraining effect is primarily a function of distance from the crack tip to the martensite and will cause the crack growing in the ferrite phase to decelerate as it approaches the martensite. The constraints imposed on plastic deformation in the ferrite will increase crack tip opening distance (CTOD) necessary for damage to accumulate and for resultant crack extension to occur. The constraining effect, in the present type of microstructure, increased with an increase in volume fraction of martensite having a continuous network enclosing ferrite phase. It has been observed (figure 5a through 5h), after a close examination of the microstructures, that the crack closed (attainment of $\Delta K_{\mathrm{th}}$ ) invariably at the tougher martensite phase in all the investigated DP structures. This further supports the observation that the FCG decreased and $\Delta K_{\text {th }}$ increased with an increase in martensite content.

\subsection{Influence of microstructure on fractographic features}

Typical fatigue fracture surface features for the DP steel at near threshold regions are given in figure 6. At near thresholds, they are characterized by transgranular cleavage resulting from the coalescence of the main crack with the branched cracks. At near threshold region, wherein the size of the crack becomes equal to or less than that of the grains, the fracture features are governed by the crystallography of individual grains (as shown in figure 6). The crack growth process is along slip planes and controlled by movement of dislocation. In other words, crack growth process occurs predominantly in single shear, in the direction of the primary slip system. This single slip mechanism leads to a zigzag crack path. Formation of secondary cracks (indicated by arrow mark) is ascribed to the liberation of atomic hydrogen from moist air in the laboratory air environment (Ravichandran et al 1986; Ravichandran and Dwarakadasa 1987). The secondary cracks are responsible for the deceleration of crack growth. It may be seen from the fractographs that the degree of secondary cracking increases with an increase in martensite content. Rough fracture surface,

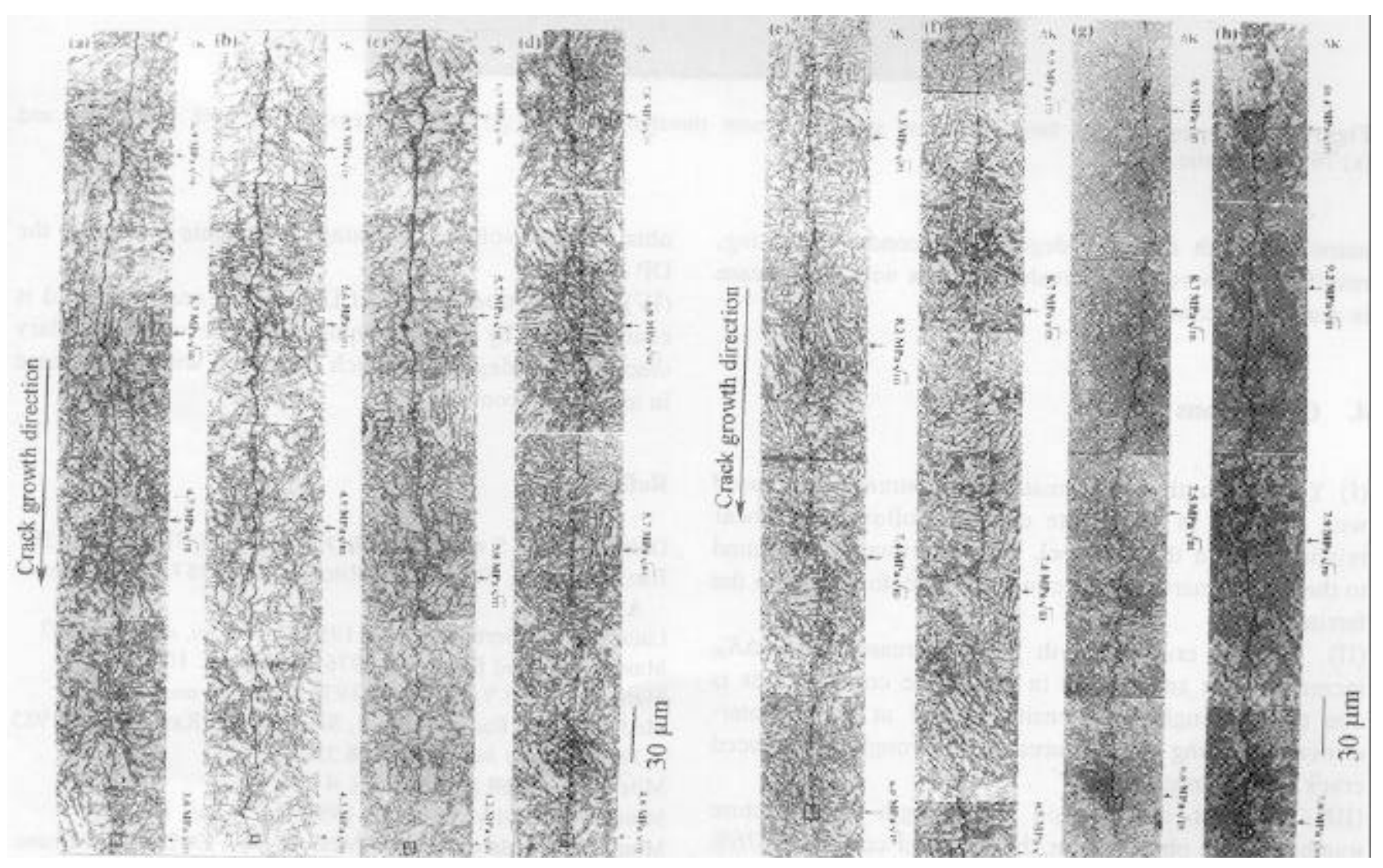

Figure 5. Crack path morphology of DP steel: (a) 32\% martensite, (b) 38\% martensite, (c) 46\% martensite, (d) $51 \%$ martensite, (e) $58 \%$ martensite, (f) $61 \%$ martensite, (g) $64 \%$ martensite and (h) $76 \%$ martensite. 

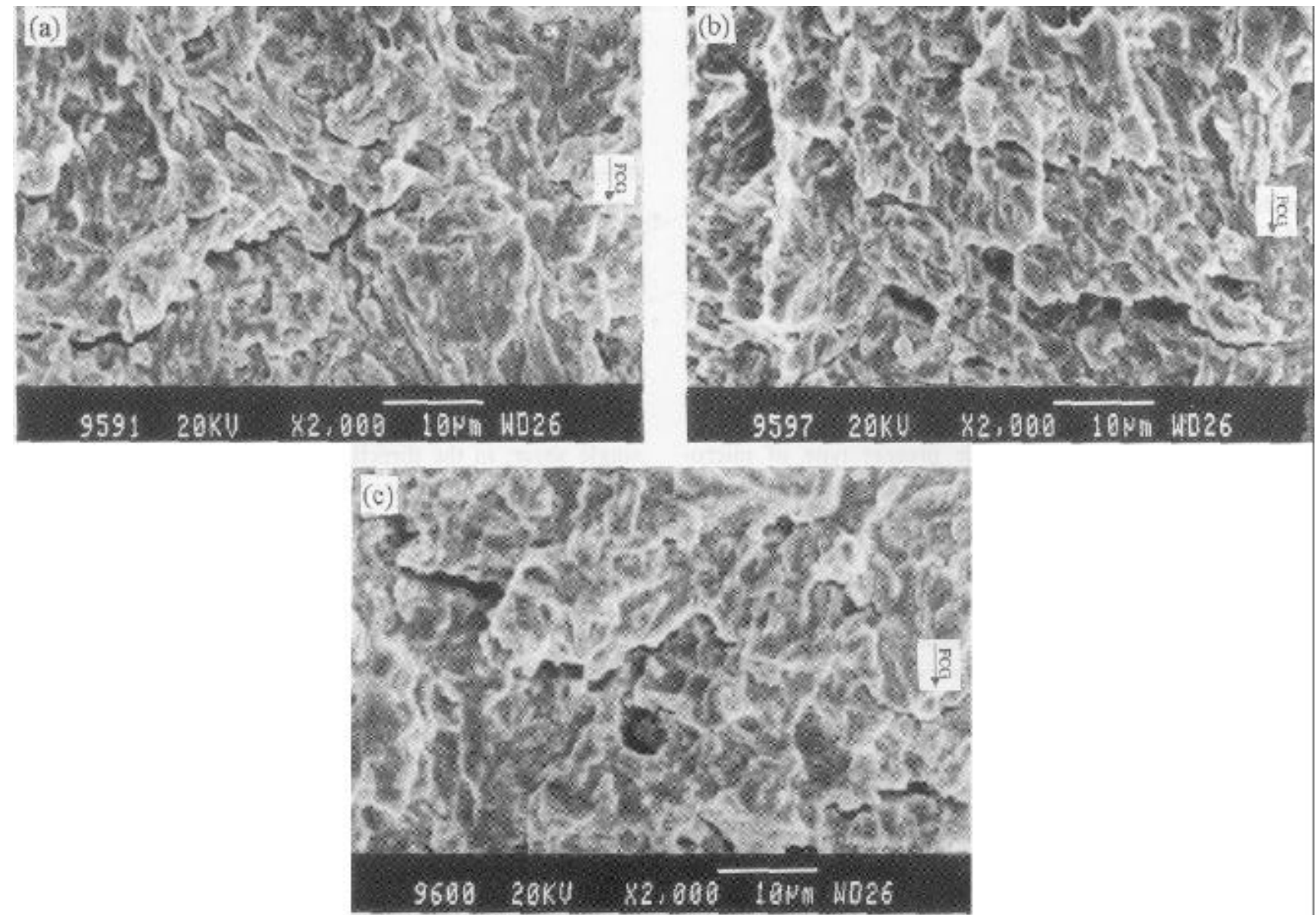

Figure 6. Fractographs of fatigue fracture surface at near threshold region: (a) 32\% martensite, (b) 51\% martensite and (c) $76 \%$ martensite.

associated with a higher degree of secondary cracking, results in an increase in threshold values with an increase in martensite content.

\section{Conclusions}

(I) Yield strength and ultimate tensile strength increased with increase in martensite content (following a linear relationship) in the DP steel. This is primarily attributed to the role of martensite in constraining deformation in the ferrite phase.

(II) Fatigue crack growth rate decreased and $\Delta K_{\text {th }}$ increased with an increase in martensite content. This is due to the tougher martensite formed at higher intercritical annealing temperatures and the roughness-induced crack closure mechanism.

(III) The best combination of strength and fracture toughness was observed for the DP steel containing $76 \%$ martensite. This increased value of fracture toughness is attributed to the lower carbon content of the martensite formed at higher intercritical annealing temperatures, to obtain higher volume percentage martensite content in the DP steel.

(IV) The fracture surface of DP steel at near threshold is characterized by a transgranular cleavage with secondary cracking, the degree of which increased with an increase in martensite content.

\section{References}

Dutta B, Suresh S and Ritchie R O 1984 Metall. Trans. A15 1193 Jian Ku Shang, Tzou L and Ritchie R O 1987 Metall. Trans. A18 1613

Lucas J P and Gerberich W W 1981 Mater. Sci. and Eng. 203

Masounave J and Bailon J P 1976 Scr. Metall. 10165

Matsuoka T and Yamamori K 1975 Metall. Trans. A6 1613

Mediratta S R, Ramaswamy V, Singh V and Rama Rao P 1985

Trans. Indian Inst. Metals $\mathbf{3 8} 350$

Mileiko S T 1969 J. Mater. Sci. 4974

Minakawa T and McEvily A J 1981 Scr. Metall. 6633

Minakawa T, Matsuo M and McEvily A J 1982 Metall. Trans. A13 439

Ramage R M, Jata K V, Shiflet G J and Starke E A 1986 Metall. Trans. A15 1291 
Rashid M S 1979 Formable HSLA and dual phase steels (New York: AIME) p. 1

Ravichandran K S and Dwarakadasa E S 1987 Metall. Trans. A18 865

Ravichandran K S, Dwarakadasa E S and Kishore K 1986 Mater. Sci. and Eng. 8311

Ritchie R O 1977 Met. Sci. 11368

Ritchie R O 1979 Int. Metall. Rev. 20205

Speich G R 1981 Fundamentals of dual phase steels (New York: AIME) p. 3
Sudhakar K V 1996 Influence of martensite content on fatigue crack growth behaviour and fracture toughness of a high martensite dual phase steel, Ph D Thesis, Indian Institute of Science, Bangalore

Suresh S, Zamiski G F and Ritchie R O 1982 In application of 2.25Cr-1Mo steel for thick wall pressure vessels (eds) G S Sangdhal and M Semchyshen (Philadelphia: ASTM) p. 755

Suzuki H and McEvily A J 1979 Metall. Trans. A10 475

Yang Y and Liu H W 1979 Fat. Eng. Mat. and Stru. 2331 